\section{Promotions- und Posterpreise, Novartis-Preis der DGP 2020}

\author{
DEUTSCHE \\ GESELLSCHAFT FÜR \\ PATHOLOGIE E.V.
}

Seit 1897 - dem Leben verpflichtet

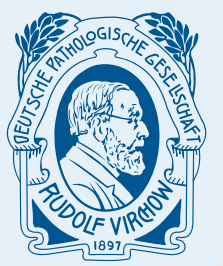

Sechs gleichwertige DGP-Posterpreise (Preisgeld: EUR 300,00)

PTP1B 6 und PTP1B 2-4 - zwei PTP1B Varianten mit unterschiedlichen Effekten auf den JAK/STAT Signalweg identifiziert im klassischen Hodgkin Lymphom.

Frau Dr. Malena Zahn, Universitätsklinikum Ulm, Institut für Pathologie, Ulm

Molekulare Analyse von Immuncheckpoint-Inhibitor „Super-Respondern“" mit nicht-kleinzelligem Lungen-Karzinom (NSCLC)

Frau Stefanie Mayer, Universitätsklinikum Ulm, Institut für Pathologie, Ulm

Molekuläre Heterogeneität in Gehirnmetastasen von Prostatakarzinomen: Eine Studie Schweizweit

Herr Dr. Antonio Rodriguez, Universitätsspital Bern, Institut für Pathologie, Bern, Schweiz

Multi-region digital spatial profiling (DSP) quantifies spatial heterogeneity of hepatocellular carcinoma tissue biomarkers.

Frau Jiaoyan Han, Universitätsklinikum Frankfurt, Dr. Senckenbergisches Institut für Pathologie, Frankfurt am Main
Prohibitins, STAT3 and SH2D4A physically and functionally interact in hepatocellular carcinoma

Herr Thorben Huth, Universitätsklinikum Heidelberg, Institut für Pathologie, Heidelberg

Digitale Genexpressionsanalyse immuntherapierter Patienten enthüllt eine Beeinträchtigung der Immunantwort aufgrund veränderter Antigenprozessierung.

Herr Michael Wessolly, Universitätsklinikum Essen, Institut für Pathologie, Essen

Ein DGP-Promotionspreise (Preisgeld: EUR 1500,00)

Die verminderte miR-196a Expression verbessert das Ansprechen gegenüber einer Peptid-basierten Inhibition des $\mathrm{HOX} / \mathrm{PBX}$-Komplexes in Zelllinien rezidivierter Chordome

Frau Carolin Seeling, Universitätsklinikum Ulm, Institut für Pathologie, Ulm

5. Novartis-Preis der DGP 2020

Machine Learning Analysis of DNA Methylation Profiles Distinguishes Primary Lung Squamous Cell Carcinomas From Head and Neck Metastases

Herr Dr. Philipp Jurmeister und Herr Dr. Michael Bockmayr, Charité Universitätsmedizin, Institut für Pathologie, Berlin 